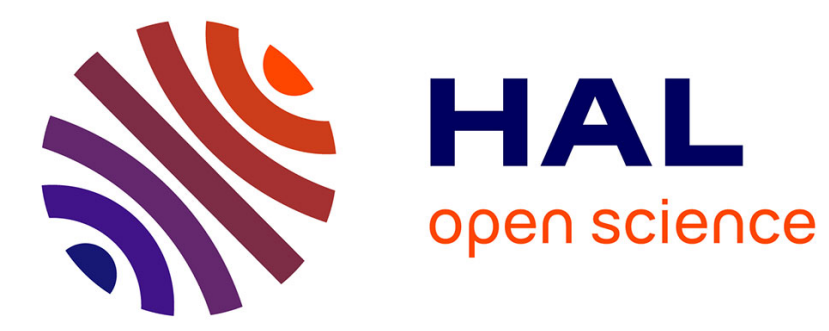

\title{
Neoclassica - A Multilingual Domain Ontology
}

Simon Donig, Maria Christoforaki, Siegfried Handschuh

\section{To cite this version:}

Simon Donig, Maria Christoforaki, Siegfried Handschuh. Neoclassica - A Multilingual Domain Ontology. 2nd International Workshop on Computational History and Data-Driven Humanities (CHDDH), May 2016, Dublin, Ireland. pp.41-53, 10.1007/978-3-319-46224-0_5 . hal-01616303

\section{HAL Id: hal-01616303 https://hal.inria.fr/hal-01616303}

Submitted on 13 Oct 2017

HAL is a multi-disciplinary open access archive for the deposit and dissemination of scientific research documents, whether they are published or not. The documents may come from teaching and research institutions in France or abroad, or from public or private research centers.
L'archive ouverte pluridisciplinaire HAL, est destinée au dépôt et à la diffusion de documents scientifiques de niveau recherche, publiés ou non, émanant des établissements d'enseignement et de recherche français ou étrangers, des laboratoires publics ou privés. 


\title{
Neoclassica - A Multilingual Domain Ontology. Representing Material Culture from the Era of Classicism in the Semantic Web
}

\author{
Simon Donig, Maria Christoforaki, and Siegfried Handschuh \\ Universität Passau, 94032 Passau, Germany \\ simon.donig@uni-passau.de \\ http://www.fim.uni-passau.de/digital-libraries/
}

\begin{abstract}
This paper presents an ontology created for classifying and researching material culture and its visual representations, that forms a part of an emerging data-driven research framework on Neoclassicism (ca. 1760-1860). The framework, named Neoclassica, unites a topdown approach to knowledge discovery, represented by the Neoclassicaontology, with innovative methods and techniques for processing multimodal data corresponding with a bottom-up approach. Below we will first describe the Neoclassica framework, discussing the epistemological considerations related with it. Second, we outline the basic objectives of the ontology and explore differences to existing thesauri, as well as relationships with existing standards (CIDOC-CRM). Third, we will give an overview of the most important classes currently provided by the ontology and illustrate the features of the multilingual approach and the descriptive power already inherent to the ontology. Finally, we will give an outlook on the next steps for developing the Neoclassica framework. ${ }^{1}$

Keywords: Ontology, Neoclassica, Material Culture, Visual Culture, Multimodality, Furniture, Architecture, Classicism, Cultural Object Documentation, History, History of Art, Cultural Sociology, Digital Humanities
\end{abstract}

\section{Introduction}

Antiquarianism played an important role in the shaping of European modernity. As a "Pan-European movement" it helped to embed "the idea held by Europeans that Europe itself epitomised the highest level of culture and civilization", concludes for instance Allison Palmer. Yet, the outreach of this "highly complex movement [...] remarkably unified under the banner of classicism" [11]: 1, spanned the globe. The Neoclassic period from 1760 to 1860 engraved antiquity in such diverse fields as architecture, gardening, the visual and the applied arts, literature and even composition, creating a wealth of artefacts from the Russian

\footnotetext{
1 The work presented in this paper has been partly funded by the German Federal Ministry for Education and Research (BMBF) under grant no. 01UG1602- Passau Centre for eHumanities (PACE)
} 
Empire's Urals to newly independent Brazil and impacting on urbanity from New York to Athens. It experienced an exchange of highly specialized craftsmen across the boundaries of territories and languages, a spread of new techniques and technologies and last but not least the emergence of almost global markets for consumer goods such as furniture and bronzes.

The Neoclassica ontology as part of the broader Neoclassica research framework provides an innovative tool to address several aspects crucial to researching the global impact of an aesthetic movement.

Albeit having been conceived less than a year ago, and being developed in full-time since March 2016, the ontology has made considerable progress. Currently with a focus on furniture and architecture, accommodating already more than 760 concepts represented in at least three languages (currently chiefly English, German and French). More than 300 of these concepts represent artefacts from the realm of material culture, particularly a broad range of furniture and furnishings, while an almost equal number of concepts describes the components that make up such artefacts.

In section 2 we give a rough image of the Neoclassica research framework and how the ontology is situated within the framework. We will then go on to give an outline of the basic objectives and current state of development of the Neoclassica ontology in section 3. The structure of the ontology so far is described in section 4 and two examples covering multilinguality and the descriptive capabilities of the ontology are given in section 5. Finally, we give an outlook on the future directions of the whole system.

\section{Neoclassica Framework}

\subsection{Epistemological considerations}

For historians of art, historians, or cultural sociologists dealing with material culture (for an introduction to the research-concept: [6], [8]) has always been a troublesome issue for methodological reasons. Arguably the discipline best fitted with the farthest reaching tool-set to address aspects of material and visual culture has always been the history of art. (For reflections on the interrelations of history and the history of art with visuals see recently [12].)

Over the last 200 years historians of art have developed the concept of style to represent a set of features shaped according to a particular aesthetic order. Stylistic analysis together with that of iconography (the symbolic dimension inherent to visual representations) and combined with the technique of building corpora of artefacts and features for a long time have been driving forces of the discipline.

Style, however, is both, one of art history's most impressive heuristic tools for classification and the expression of particular historic conditions, cultural grammars and discursive conjunctions [10]. Any process of classification will inadvertently be faced with selection and, as every scholar of the Humanities is well aware, selecting is a concious or unconscious process of meaning-making, 
e.g. by giving weight and value to a chosen trait or object over another. The select body can be considered as a canon, endowed with scholarly authority. The shape of such bodies, and the attributions made to them, can essentially be understood as time-bound efforts of meaning-making [1].

Any scholarly effort dealing for instance with aesthetic programs has to be well aware of this duality, particularly when transferring traditional knowledge representations from the realm of culture to the Semantic Web [13]. A research framework based on these premises should in our eyes be aware of traditional orders of knowledge representation and deliver both, tools to analyse, question and understand them and provision new, more transparent tools of knowledge discovery.

\subsection{The Proposed Framework}

We propose a framework called Neoclassica which explores this duality by accommodating traditional knowledge representation as a formal ontology (top-down approach) and data-driven knowledge discovery (bottom-up approach), where cultural patterns will be identified by means of algorithms in statistical analysis and machine learning, having in particular the potential to uncover hitherto unknown patterns in the source data. The outcomes of both approaches will be united in a consistent, unified formal knowledge representation.

Partners from the GLAM will provide us with multimodal artefacts to be processed by the different framework components while in the end we hope to provide a research platform allowing different institutions and researchers to upload content that will be classified both automatically and with human assistance.

The Neoclassica-framework aims to be a useful tool for researchers to uncover and clarify among other things the spread of cultural patterns, better our understanding of cultural exchange processes, trace the emergence of new or hybridized aesthetic forms, or to deconstruct and analyse visual canons, to name but a few.

\section{Why a New Domain Ontology?}

\subsection{Basic Objective}

The Neoclassica-ontology offers a formalized encoding of domain-expert knowledge in order to make it accessible to complex research questions with the use of a computer. Thus it offers venues to make the domain knowledge commensurable with the bottom-up module. [7]: 464 argues that specialized terminology in cultural heritage research is chiefly used as an intellectual tool for hypothesis building. Our aspiration is that the Neoclassica ontology will eventually be used as such a tool, establishing a controlled vocabulary that not only is research-

oriented and multilingual but also reflects the different shape of the represented concepts in different languages. 
So far we are not aware of any broadly accepted ontologies in this specific area. However a seizable amount of concepts we are interested in, is represented by various well established thesauri such as Getty's Arts and Architectural Thesaurus (AAT) ${ }^{2}$ the German Möbeltypologie, ${ }^{3}$ see also [3]), the French architectural thesaurus Thésaurus de la désignation des ouvres architecturales et des espaces aménagés, ${ }^{4}$ and the furniture thesaurus Thesaurus des Objets Mobiliers [15], see aso [14], or the Spanish Diccionario de Mobiliario, ${ }^{5}$ all of them essentially developed for the purposes of documenting cultural objects in the realm of museums and cultural conservation in general.

Under- and overspecification is an issue in this context because most established thesauri are conceived with a more general focus in mind. They hence lack a lot of domain-specific concepts or concepts of regional origin that we require, while on the other hand providing a lot of modern concepts that eventually might even taint the semantics of a concept if compared with a period example.

To give an example of the last case, the historic term pantry describes a dedicated space connected to the kitchen or dining room used to store both food and cooking utensils; ${ }^{6}$ nowadays pantry usually refers to a piece of cabinetry serving a similar function. While in the period in question a pantry might have been equipped with specialized pieces of furniture, no dedicated concept for these existed. As the term pantry slowly migrated from denoting a dedicated space to a broader type of case furniture, the ontology accommodates the term only to denote said space. Period furniture that nowadays often are referred to as pantries are in turn accommodated by other period terms such as credenza, sideboard or buffet bas.

To illustrate the effects of culturally induced underspecification let us provide another example. The ontology was to accommodate a type of artefact common on the continent, yet almost unknown to Great Britain: a piece of furniture with two distinct and visually separated units (for an illustration see figure 2 below) consisting of a small, recessed bookcase with a double door, like a dwarf bookcase, placed on top of a side-cabinet with a double door.

The AAT for instance does not accommodate such a concept but has other concepts that represent constructionally similar types of furniture such as secretary bookcases or chests-on-chests. The French language, however, offers the concept of a meuble à deux corps (literally: furniture with two bodies) to describe such artefacts (cf. étagère-bibliotheque in [15]: 158). The German Möbeltypologie, in turn, does also not offer a dedicated concept for this type of artefact, coming closest by defining an Aufsatzschrank or Armoire à deux corps as consisting of

\footnotetext{
${ }^{2}$ http://www.getty.edu/research/tools/vocabularies/aat/index.html

${ }^{3}$ http://museum.zib.de/museumsvokabular/documents/systematik-moebel.pdf

${ }^{4}$ http://data.culture.fr/thesaurus/page/ark:/67717/T96

${ }^{5}$ http://tesauros.mecd.es/tesauros/tesauros

${ }^{6}$ Cf. "Office", in: Ramée, D.: Dictionnaire général des termes d'architecture en Français, Allemand, Anglais et Italien. C. Reinwald, Paris (1808): 298, see also "Paneterie" idem: 308
} 
a cabinet unit often placed on top of another type of furniture like a chest of drawers, buffet or table.

We wanted the term to be more generic and have thus decided to accommodate a type of case furniture, called Meuble à deux corps, comprising artefacts showing constructional similarity, such as bookcase on chest, bookcase on sidecabinet, bureau bookcase (including cylinder-top bureau bookcase and secretary bookcase), chests on chests or double corner cupboard.

As our approach is focusing on a specific domain, we decided that the Neoclassica ontology should also reflect the historical semantics of concepts. For example the concept of a meuble à deux corps can be established from sources such as Charles Percier's 1812 treatise on interior decoration. Whenever possible we strive to provide concepts, labels and scope-notes based on extensive research in period sources such as Daniel Ramée's multilingual architectural dictionary, Antoine Quatremère de Quincy's historical dictionary of architecture, Henry Havard's dictionary of furniture and interior design or period publications from the field such as for instance Joseph Danhauser's and Thomas Sheraton's pattern-books or Thomas Hope's treatise on interior decoration. ${ }^{7}$

\subsection{CIDOC-CRM and Neoclassica}

The Neoclassica-ontology is focused on driving research in the Humanities. So while it can be used to provide cultural object documentation, relies on well defined data and as a side-effect will certainly produce such data, our focus is currently on facilitating importing and accommodating existing data in the research framework.

Since CIDOC-CRM is an international standard its concepts can be used as a reference point both by us and our prospective partners. We thus try to develop our ontology to be (ideally) compatible with at least the reduced form of CIDOC-CRM as presented in the most recent iteration in [4].

We are interested in expressing concepts like (E4 Period, E52 Time-Span and E53 Place) to represent for instance the Biedermeier Period and the relationships P7 took place at and P4 has time-span, and P10 falls within to represent that it took place in the countries of the German tongue (for instance the Grand-Duchy of Badenia, the Kingdom of Prussia, the Helvetic Republic, or the German-speaking parts of Cisleithania, etc.), Poland, Bohemia, Russia, or the Baltic region for different time spans, each. We are also interested in concepts

\footnotetext{
${ }^{7}$ Danhauser, J.: Wiener Möbelformen, Wien (1801), Sheraton, T.: The cabinet dictionary. To which is added a supplementary treatise on geometrical lines, perspective, and painting in general. Smith, London (1803), Hope, T.: Household Furniture and Interior Decoration, executed from designs, Bensley, London (1807), Ramée, D.: Dictionnaire général des termes d'architecture en Français, Allemand, Anglais et Italien. C. Reinwald, Paris (1808); Percier, C.: Recueil de décorations intérieures. Didot, Paris (1812), Quatremère de Quincy, A.: Dictionnaire historique d'architecture. Librarie d'Adrien Le Clere et Cie., Paris (1832), Havard, H.: Dictionnaire de lameublement et de la décoration depuis le XIIIe siècle jusquà nos jours. Librairies-Imprimeries réunies, Paris (1887).
} 
such as E12 Production to denote the production-event and E39 Actor as well as its subclass E21 Person further to be specialized in our model as craftsman, architect, artist (painter etc.), maecenas or proprietor. Last but not least, concepts like E55 Type will enable us to accommodate thesauri about materials, techniques or iconography.

\subsection{Current State}

Currently the ontology is focused towards material artefacts and visual representations in a broad variety of media (historical photographs, paintings, prints etc.). At the present moment the ontology contains only hierarchies describing types of artefacts and their components as well as the $i s_{-}$composed_of relationship that will permit to describe the structure of the objects in terms of their parts. This was motivated by the need to combine the feature-extraction and object classification (cf. [2]) approach (bottom-up) described in section 2 with the domain-knowledge representation approach (top-down) that we intend with ontology.

\section{The Structure of the Neoclassica-ontology}

The central concept of the ontology is currently the Artefact which is equivalent to the concept E22 Man-Made Object in the CIDOC CRM standard [4]. It denotes all man-made objects. This artefact - for instance a piece of furniture or furnishing - can be described both as a concept and by its structure.

Currently the basic concepts comprise five classes and a corresponding trove of subclasses.

They include components of artefacts (Component), what would traditionally be described as architecture (Built_design_artefact) and all movable equipment fitted to those built structures (Interior_design_artefact).

The Component class comprises subclasses that describe the structure of objects. One of them (Architectural_element) describing the basic shapes that can be broken down only to geometrical forms (for instance ornaments such as various mouldings, or structural elements such as an arch). We defined the other (Architectural_feature) as describing forms aggregated from architectural elements and / or other features. Features could comprise for instance a particular type of a bedpost, door or foot.

Furniture and furnishings are represented as subclasses of the class Interior_design_artefact. It is currently the most fleshed out class in the ontology, comprising furniture (264 concepts) and furnishings (68 concepts). The Architectural_element class currently comprises 110 architectural elements, the Architectural_feature class 167 features and the Structural_component class 75 components.

Objects are related to their components via the is_composed_of property having as domain and range the class Artefact since in our subject area everything is composed only of man-made objects. 


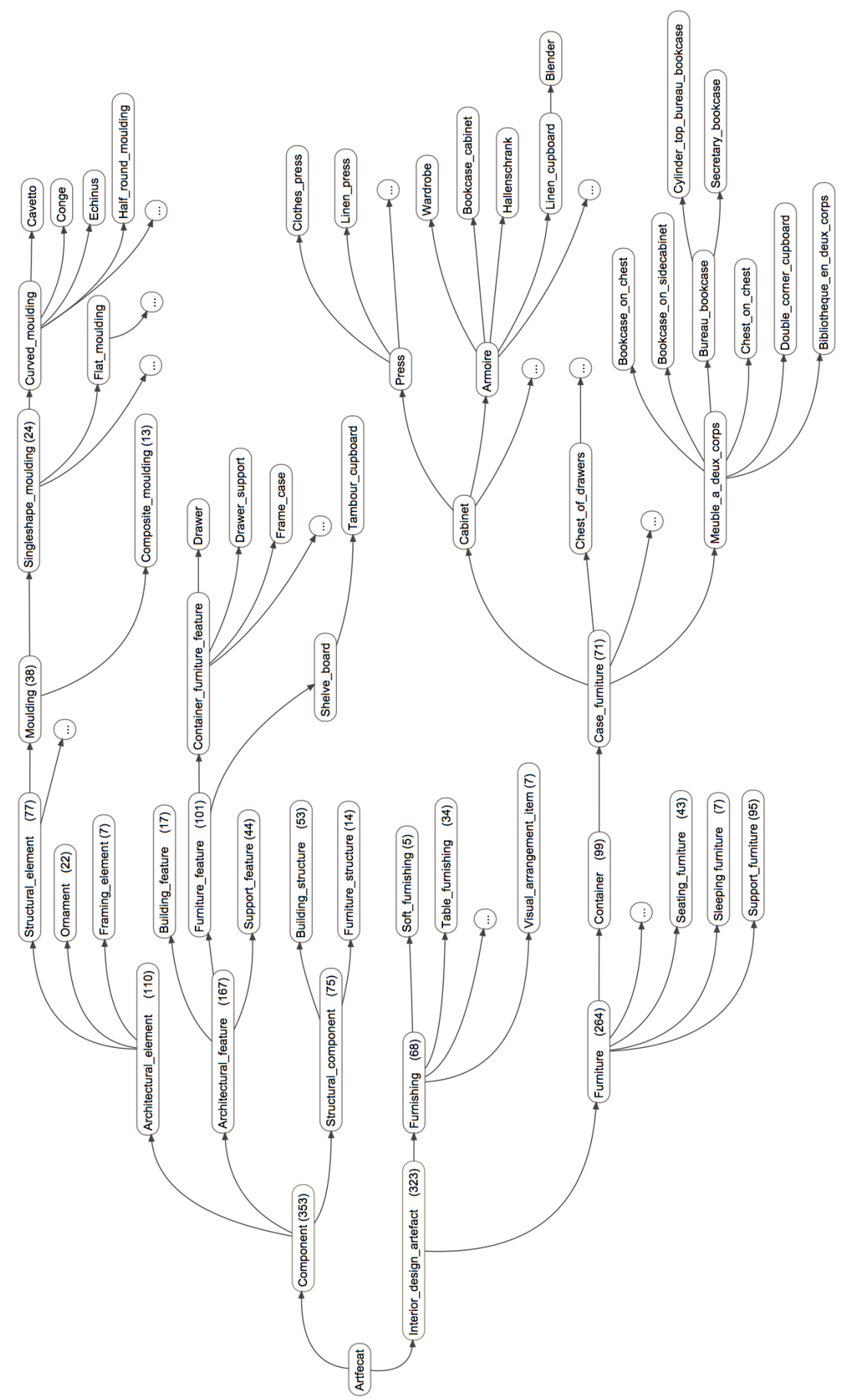

Fig. 1. The most important classes in the Neoclassica hierarchy. The number of concepts represented by each class is given in brackets 


\section{$5 \quad$ Practical examples}

\subsection{Multilinguality and the presence / absence of concepts in languages}

One of the great challenges, an ontology that is both research oriented and multilingual will face, is the presence or absence of concepts in various languages.

A glaring example we encountered was the concept of a continental armoire and the British concept of a press. While an armoire can be described as an upright wardrobe usually with fixtures for hanging clothing and sometimes with shelving or drawers in the interior, the press denotes a sort of cupboard, where the clothes or linens are entirely put on shelving or in drawers.

While an armoire is relatively uncommon to the realm of the English tongue (as denoted by the use of a French loan word), it is at least not entirely alien. The press, however, is essentially an unknown concept in Germany and France.

This poses interesting domain problems and modelling issues, because

- the German term Schrank and the French armoire are usually used interchangeably and denote an identical concept,

- clothes and linen presses have no conceptual counter model on the continent,

- and even worse, the distinction of cupboard (with shelving) and wardrobe is only valuable in English, as both terms may be represented by Schrank and armoire in German or French respectively.

To address this we decided to represent concepts unknown to a language by specifying their name in their language of origin as a label. We introduced two generic classes (Container and its subclass Case_furniture to accommodate all possible types of concepts. (The latter corresponding to the AAT term case furniture). To the case furniture class we added the sub-class Cabinet comprising in turn the classes Press and Armoire and their respective subclasses because we see them as functional (albeit not constructional) equivalent. Due to their relation we can treat Armoire and Schrank as labels for the same concept. We then went on to flesh out the Armoire class by adding essentially the functional equivalents to the two presses and any constructional variant.

This illustrates the challenge we face by having both a narrow and a wide perspective in our subject material. Narrow in the sense that we deal only with specific period artefacts (Neoclassical artefacts) and wide in the sense that we trace these artefacts in different places and chronological periods and in variations of Classical styles. We hence had to represent concepts that are either identical, overlapping or disjoint across multiple cultural domains in a synthetic approach.

\subsection{Descriptive power}

Figure 2 shows a German cherrywood Biedermeier bookcase on a side cabinet originally from the refectory of a monastery in the region of Oberschwaben, dating around 1827-1830. We have chosen the artefact to demonstrate some of 
the descriptive capabilities of Neoclassica and also the conceptual refinement of the ontology required to accommodate the artefact. (We concentrate only on the most important features below.)

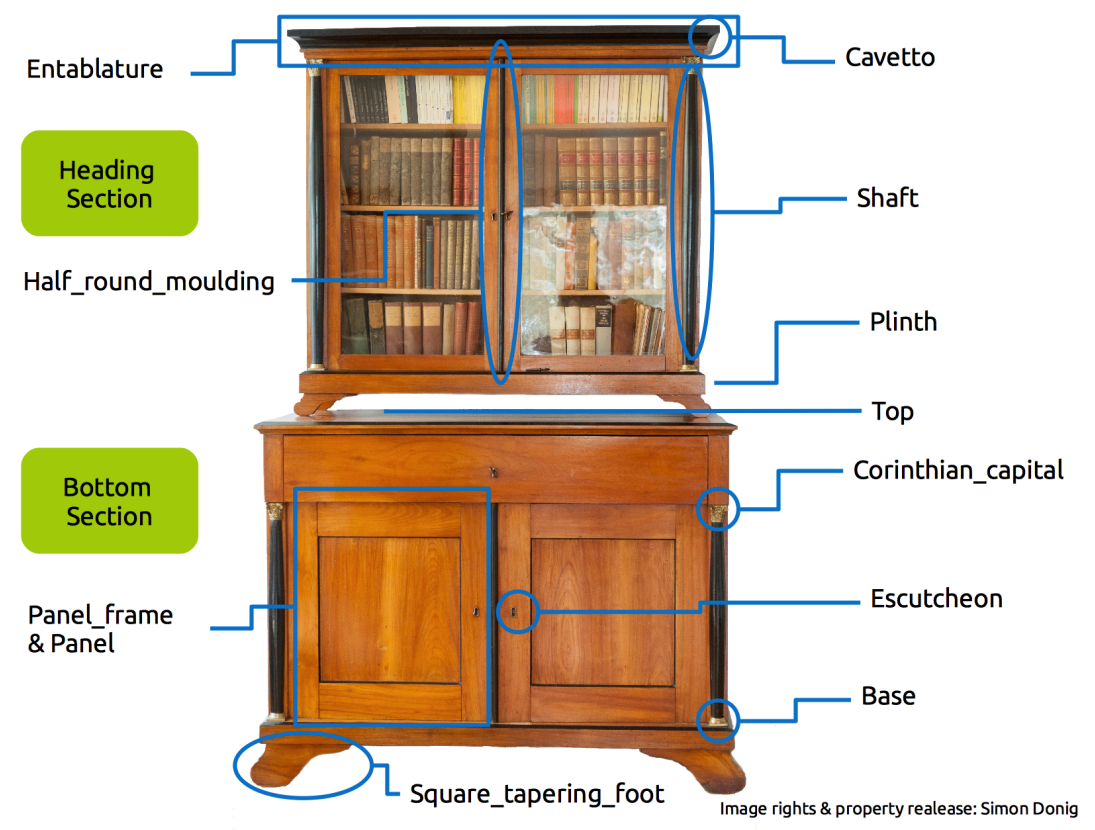

Fig. 2. A German Biedermeier Bookcase on Side Cabinet with Neoclassic features ca.1827-30

Besides providing means for classifying types of artefacts, the ontology allows to document their structure and components. In our example it provides the concept of heading- and bottom-section used to describe the specific object.

Both sections possess a double door, consisting of a pair of panel frames and a pair of panels one pair with glazing, a pair executed in wood. The bottom-section also has a top drawer. Each section sports furthermore a pair of half-columns consisting of a base and a Corinthian capital. The shaft of the column is convex shaped. Other features accommodated by the ontology include for instance the square tapering feet combining profiled cyma recta- and cyma reversa-shapes, escutcheons, shelve-boards in the heading section or the ebonized half-round staffs dividing the sections vertically.

Below we include some RDF snippets to illustrate how these concepts are realized in our system.

This bookcase on side cabinet corresponds to the RDF class http://www.neoclassica.network/ontology\#Bookcase_on_side_cabinet

neoclassica: Bookcase_on_side_cabinet

rdf : type

owl: Class

rdfs: subClassof 


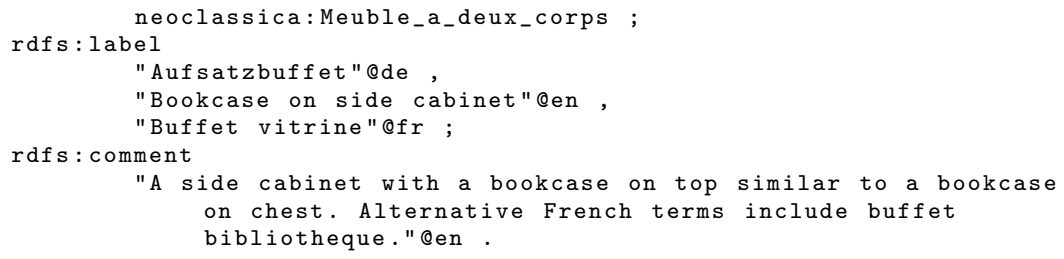

The specific Biedermeier bookcase is an instance of this class and we describe its structure using the is_composed_of object property.

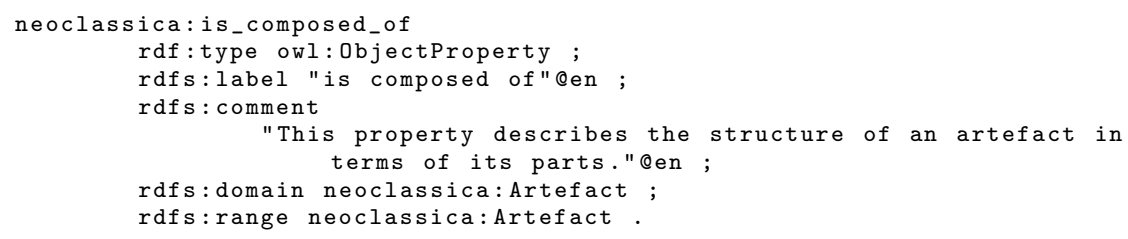

The RDF code for the specific object is

neoclassica: Biedermeier_bookcase

rdf : type

neoclassica:Bookcase_on_side_cabinet,

Further on its constituent parts are described (double doors, feet, shelves, panels, panel frames, etc. )

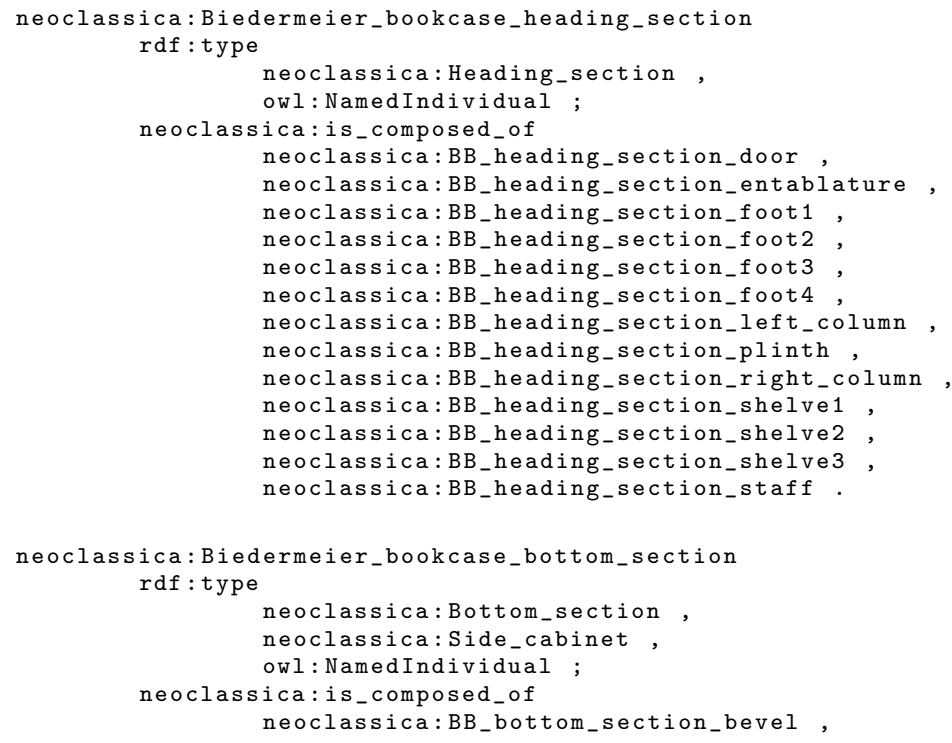




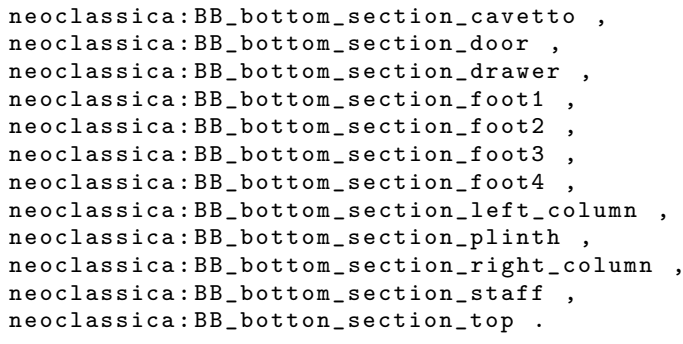

Each of these parts is further classified using the Component hierarchy (see figure 1).

For example the entablature of the heading section is an instance of class http://www.neoclassica.network/ontology\#Entablature .

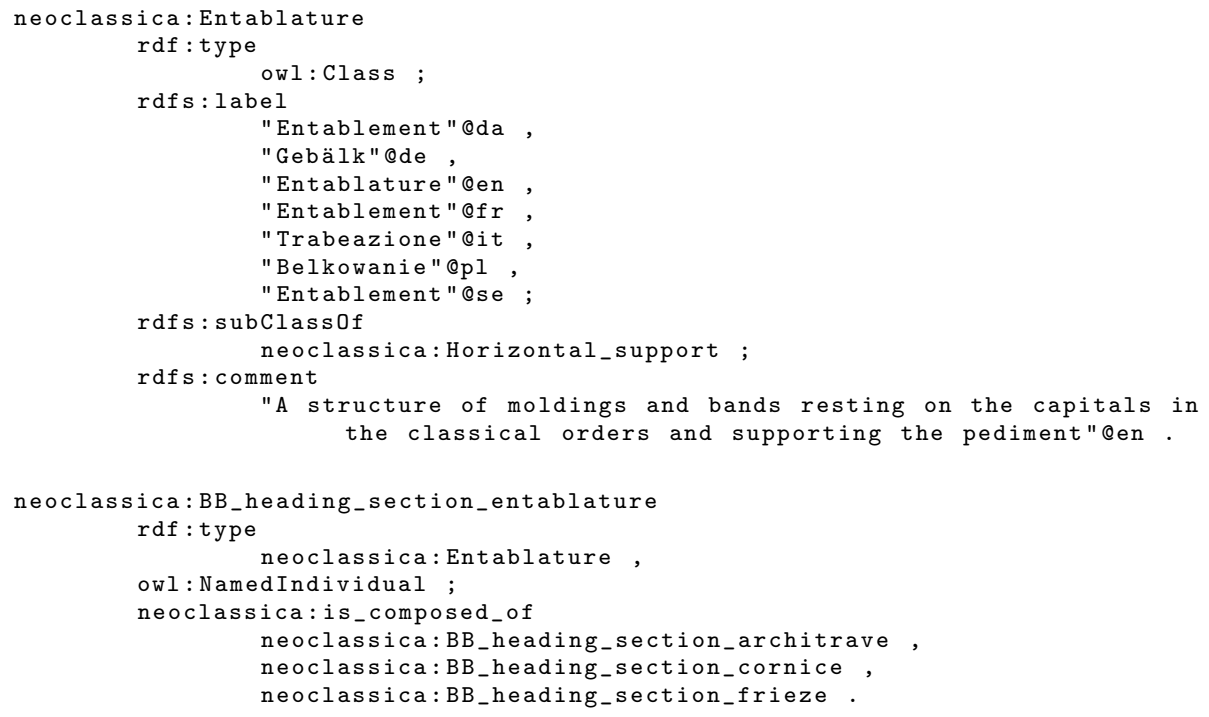

Further on we define the cornice both as an instance of class

http://www.neoclassica.network/ontology\#Cornice and the class

http://www.neoclassica.network/ontology\#Cavetto since the one refers to the structural feature and the other to the kind of moulding that the cornice is.

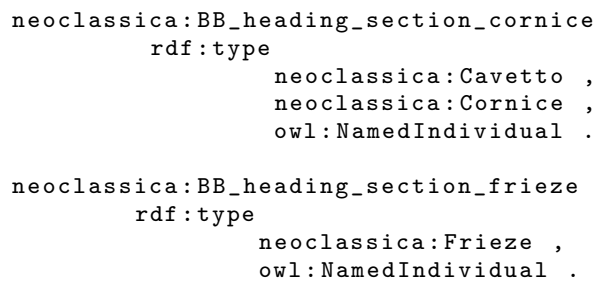

The class definitions for Cornice and Cavetto are provided below.

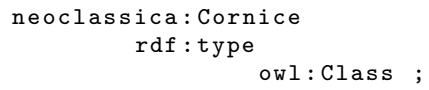




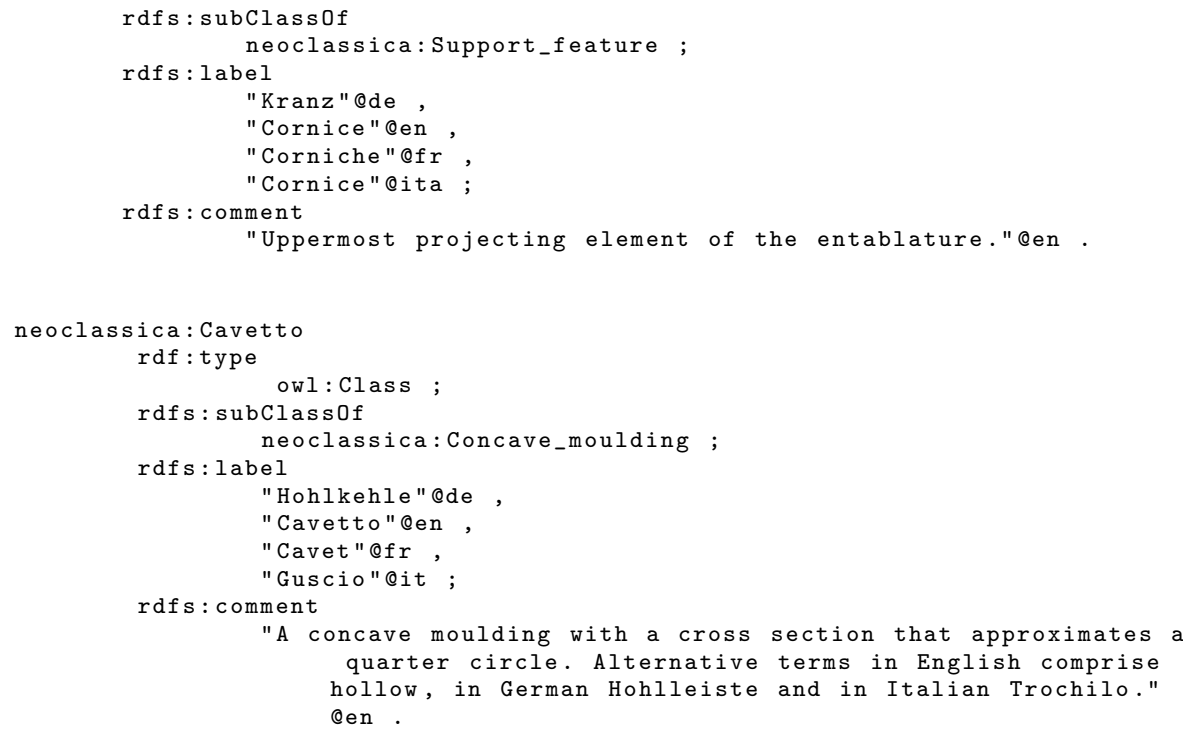

\section{Conclusion and outlook on future development}

In this paper we presented the Neoclassica-ontology as part of the Neoclassica framework, the latter aiming to provide useful tools for researchers combining existing domain knowledge with the power of statistically analyzing multimodal data. The ontology so far includes concepts for representing mainly interior design artefacts and their components according to their form.

At the time of writing we strive to accommodate architecture and the built environment in the ontology. In the near future we will extend it to represent materials and techniques used in the creation of artefacts and to accommodate conceptual objects such as iconography, possibly by using open linked data to existing classification systems like ICONCLASS (http://iconclass.org/). Furthermore we would like to accommodate spacial information such as the placement of furniture in rooms and the arrangement of artefacts in groups.

We aspire to build a strong community around the Neoclassica platform that will contribute data to the Neoclassica research database, use Neoclassica as a research tool and disseminate the results. In this light we will also approach new institutional partners holding collections and intensify our collaboration with established partners such as the Kulturstiftung DessauWörlitz, a UnEScO world-heritage site conserving an almost untouched ensemble of manor houses, gardens and furniture, most of them bearing Neoclassic traits, to bring a first prototype of the Neoclassica research-database into existence.

The Neoclassica ontology and the respective examples will be freely obtainable in the near future under a CC License from http://www.neoclassica.network. 


\section{References}

1. Assmann, A: Speichern oder Erinnern? Das kulturelle Gedächtnis zwischen Archiv und Kanon. In Csáky, M. and Stachel, P. (eds.) Speicher des Gedächtnisses: Bibliotheken, Museen, Archive (2) : Die Erfindung des Ursprungs, die Systematisierung der Zeit. pp. 15-30 Passagen, Wien (2000).

2. Bernmeitinger, B.: Design and Evaluation of Multimodal Distributional Semantics for Automatic Style Recognition. University of Passau (2016).

3. Böth, G. ed: Möbel - eine Typologie für Museen und Sammlungen. Dt. Kunstverl., München [e.a.] (2005).

4. Le Boeuf, P. et al. eds: Definition of the CIDOC Conceptual Reference Model, Version 6.2.1, (2015).

5. Bruni, E. et al.: Multimodal Distributional Semantics. Journal of Artificial Intelligence Research. 49, 1, 1-47 (2014).

6. Colloredo-Mansfeld, R.: Introduction - Matter Unbound. Journal of Material Culture. 8, 3, 245-254 (2003).

7. Doerr, M.: Ontologies for Cultural Heritage. In: Staab, S. and Studer, R. (eds.) Handbook on Ontologies. pp. 463-486 Springer Berlin Heidelberg (2009).

8. Hicks, D.: The Material-Cultural Turn: Event And Effect. In: Hicks, D. and Beaudry, M.C. (eds.) The Oxford handbook of material culture studies. pp. 25-98 Oxford Univ. Press, Oxford [u.a.] (2010).

9. Hiippala, T.: The interface between rhetoric and layout in multimodal artefacts. Lit Linguist Computing. 28, 3, 461-471 (2013).

10. Hoppe, S.: Stil als Dünne oder Dichte Beschreibung. Eine konstruktivistische Perspektive auf kunstbezogene Stilbeobachtungen unter Berücksichtigung der Bedeutungsdimension. In: Hoppe, S. et al. (eds.) Stil als Bedeutung in der nordalpinen Renaissance. Wiederentdeckung einer methodischen Nachbarschaft. pp. 48-103 Schnell u. Steine, Regensburg (2008).

11. Palmer, A.L.: Historical Dictionary of Neoclassical Art and Architecture. Scarecrow Press, Plymouth (2011).

12. Schober, A.: Verführung durch visuelle Kultur. Zur aktuellen Selbstbefragung von Geschichte und Kunstgeschichte. In: Bruhn, M. and Borgmann, K. (eds.) Sichtbarkeit der Geschichte: Beiträge zu einer Historiografie der Bilder. pp. 35-48 HArthist and H-Soz-u-Kult, Berlin (2005).

13. Veltman, K.H.: Towards a Semantic Web for Culture. Journal of Digital Information. 4, 4, (2006).

14. Verdier, H. ed: Système descriptif des objets mobiliers. Sous-direction des études, de la documentation et de l'inventaire, Direction de l'architecture et du patrimoine, Ministère de la culture et de la communication, Paris (1999).

15. Verdier, H. ed: Thesaurus des objets mobiliers. Éditions du Patrimoine, Paris (2001). 